\section{Obstruktion der oberen Atemwege}

Helga Peter

Marburg, Deutschland

\section{Synonyme}

Partieller Verschluss der oberen Atemwege

\section{Englischer Begriff}

upper airway obstruction (UAO)

\section{Definition}

Der Ausdruck ist im Zusammenhang mit $\gg$,Schlafbezogene Atmungsstörungen“ gebräuchlich und betrifft üblicherweise die funktionelle, im Schlaf phasenhaft auftretende Einengung der oberen Atemwege, wie sie für die \ „Obstruktive Schlafapnoe" charakteristisch ist. Neben Substanzen wie Alkohol, Schlafmitteln und Hormonen sind auch Nervenläsionen als Auslöser bekannt. Ebenso gibt es anatomische Prädispositionen: Adipositas, Fetteinlagerungen im Halsbereich, stark eingeengte nasale Atemwege, vergrößerte Adenoide und Tonsillen, ein elongiertes Gaumensegel, ein verdickter Zungengrund sowie skelettale Besonderheiten wie beispielsweise $>$ „Retrognathie“ oder ₹ „dolichofazialer Gesichtstyp“.

Siehe auch

- „Obstruktive Schlafapnoe“

- „Schnarchen“

- „Kiefer- und gesichtschirurgische Verfahren zur Therapie der Obstruktiven Schlafapnoe“"

- \,HNO-ärztliche Verfahren zur operativen Therapie der Obstruktiven Schlafapnoe“

- „ „Oral Appliances“ 